Journal of Advanced Research in Fluid Mechanics and Thermal Sciences

\title{
Performance and Emissions of Diesel Engine with Circulation Non- Surfactant Emulsion Fuel System
}

\author{
Reashed Tasvir Omi ${ }^{1}$, Wira Jazair Yahya ${ }^{1}$, Hasannuddin Abd Kadir ${ }^{2,}{ }^{*}$, Arif Fahim Ezzat Chan ${ }^{1}$, Ahmad \\ Muhsin Ithnin ${ }^{1}$, Nik Rosli Abdullah ${ }^{3}$, Md Mujibur Rahman ${ }^{1}$, Usama Tahir ${ }^{1}$

\footnotetext{
1 Advanced Vehicle System, Malaysia-Japan International Institute of Technology (MJIIT), Universiti Teknologi Malaysia, 54100, Kuala Lumpur, Malaysia

2 Faculty of Mechanical Engineering, Universiti Teknologi MARA (UiTM) Johor, Campus Pasir Gudang, 81750 Masai Johor, Malaysia

3 Faculty of Mechanical Engineering, Universiti Teknologi MARA (UiTM), 40450 Shah Alam, Selangor, Malaysia
}

\section{ARTICLE INFO ABSTRACT}

\section{Article history:}

Received 24 November 2020

Received in revised form 10 April 2021

Accepted 14 April 2021

Available online 4 May 2021

\section{Keywords:}

Diesel engine; nitrogen oxides; emulsion fuel; non-surfactant

\begin{abstract}
Diesel engine is known for its durable operation and capability of utilizing various type of fuels, however, dangerous exhaust emissions are emitted from diesel engines. Nonsurfactant emulsion fuel is a potential fuel for diesel engine to reduce for Nitrogen oxides $\left(\mathrm{NO}_{\mathrm{x}}\right.$ ) and Particulate matter (PM) emission compare to conventional diesel fuel in a diesel engine. In this study, emulsion fuel was prepared using a mixer known as Circulation Non-Surfactant Emulsion Fuel System. The study carried out with different water percentages in the emulsion fuel given as follows: $3 \%, 6 \%$, and $9 \%$ and at a different engine load condition from 1-4 kW with a constant speed of $3200 \mathrm{rpm}$. Results show that, $6 \%$ emulsion fuel shows average $4.38 \%$ reduction in $\mathrm{NO}_{\mathrm{x}}$ emission and $1.10 \%$ reduction in fuel consumption. $9 \%$ emulsion fuel show higher amount of $\mathrm{CO}$ emission compare to Diesel while it reduces $\mathrm{CO}_{2}$ emission. Overall, $6 \%$ when prepared are recommended for the formation of non-surfactant emulsion fuel.
\end{abstract}

\section{Introduction}

Transport sector and other industries depends heavily on fossil fuels for the energy, which puts an extensive pressure on humanity and environment. Limited supplies and rising diesel prices have raised questions about the security of energy and the economy, while pollutions are contributing to environmental degradation and health issues [1]. Generally, diesel engine is much more durable compare to gasoline engine, yet diesel engine is more expensive to manufacture. Diesel engine that is likely to last longer and provides years of routine maintenance services. In addition, diesel engines are always known for their reliability and fuel consumption. Despite of preferable usage of diesel engine, dangerous exhaust emission especially Particulate Matter (PM), Nitrogen Oxides (NO ${ }_{x}$ ), Carbon Monoxide (CO) and Carbon di-oxide $\left(\mathrm{CO}_{2}\right)$ are emitted from diesel engine [2-5].

\footnotetext{
* Corresponding author.

E-mail address: hasannuddinabdkadir@gmail.com
}

https://doi.org/10.37934/arfmts.82.2.96105 
Alternatively, one of the ideal solution for fuels to traditional diesel fuel is water-in-diesel (W/D) emulsion, which can increase a diesel engine's combustion efficiency and help decrease hazardous emission from exhaust, in particular $\mathrm{NO}_{x}$ and PM [6-8]. This is due to the most influential feature of the phenomenon of micro-explosion [9]. $\mathrm{NO}_{x}$ and $\mathrm{PM}$ emissions are also influenced by the density of the fuel. Less density of fuel will minimize $\mathrm{NO}_{x}$ and PM but increase $\mathrm{CO}$ and hydrocarbon [10]. Water droplets reduce the fuel density in W/D which effects on emission and combustion within the engine which inspires researchers more to conduct an investigation more with W/D in the process of engine combustion process [11]. Direct water injection and fumigation in the engine requires engine modification but it provides water in to the engine at adjustable rate according to the engine load and speed. W/D emulsion comparatively reduces $\mathrm{NO}_{x}$ and $\mathrm{CO}$ emission in comparison to other water injection methods without modifying the engine configuration [12]. It has also been shown that W/D does not contaminate lubricant oil such as the methods of direct fuel injection and fumigation that add water in a separate step [10]. Micro-explosion phenomena in W/D emulsion, When the droplets are present in the fuel undergo an instant overheated phase shift, which results in a secondary atomization of the fuel [13]. Some researchers found that the use of $W / D$ decreases $\mathrm{NO}_{\mathrm{x}}$ formation by up to $40 \%$ [14].

The high temperature during combustion helps to form $\mathrm{NO}_{\mathrm{x}}$, water content in W/D emulsion reduces the combustion temperature thus helps to reduce the formation of $\mathrm{NO}_{\mathrm{x}}[15]$. W/D emulsion reduces fuel consumption by $3.89 \%$ compare to neat diesel owing to the micro explosion phenomena in the engine combustion chamber which increases the efficiency of the engine combustion [5]. Study conducted in single cylinder; 4 stroke engine maximum decrease of PM is $37.42 \%$ at maximum load of $4 \mathrm{~kW}$ which suggests that emulsion fuel combust more effectively at higher engine loads [5]. The root causes of emissions of PM are lower fuel temperature, rapid water evaporation and increased soot precursor oxidation due to $\mathrm{OH}$ radicals addition [16]. If the water droplet is smaller, the mass of residual water or even vanishes before the droplets are heated to the saturation temperature during the micro-explosion phenome, resulting in a weak explosion occurring [17]. Some researcher found that $\mathrm{CO}$ emission decreases with a low load condition using emulsion fuel [18]. Because of the presence of water in the emulsion fuel, greater $\mathrm{CO}$ emissions occur because of the lower combustion temperature [19]. The temperature is not enough to convert $\mathrm{CO}$ to $\mathrm{CO}_{2}[20]$.

The aim of this paper is to explore on engine performance and emissions with different percentages of water of non-surfactant W/D (NWD) with a load of (1-4) kW and a continuous speed of $3200 \mathrm{rpm}$. The NWD emission with different water percentages of $3 \%, 6 \%$ and $9 \%$ compared with D2. Circulation non-surfactant emulsion fuel system is a new type of system where water and diesel are mixed without using ultrasonic mixer. The aim to use circulation system (CS) is to reduce components and energy using the previous system. Ultrasonic mixer requires energy to generate emulsion fuel by using CS it can reduce energy consumption without the use of the ultrasonic mixer and also increase emulsion fuel stability.

\section{Methodology}

\subsection{Experimental Setup}

Two forms of fuel that were checked which are neat diesel fuel D2 and NWD with different water percentages given as follows: $3 \%, 6 \%$ and $9 \%$. NWD was prepared by using a CS that has been installed before the fuel goes to the engine.

Figure 1 shows the overall CS configuration in which the fuel from the fuel tank flows through the fuel channel into the mixing system. CS is a powerful combination of mixing that can emulsify diesel and water without using any surfactant. The MS was positioned near the engine to supply the NWD 
directly in the engine before being separated as no surfactant was used during the experiment. NWD sample was taken from the return fuel line during an engine test and it was noted that the NWD was still in that same stage, without any distinctive division. This led to the conclusion that even after being pumped into the engine, the NWD was stable. Throughout the testing the engine was running smoothly without any problems, presumably indicating that the water had yet to be separated. Both water and diesel were stored in two separate tanks. Both the NWD continuously and fed directly to the engine from the MS. With a solenoid valve, the amount of water injected into the CS from a water tank is controlled.

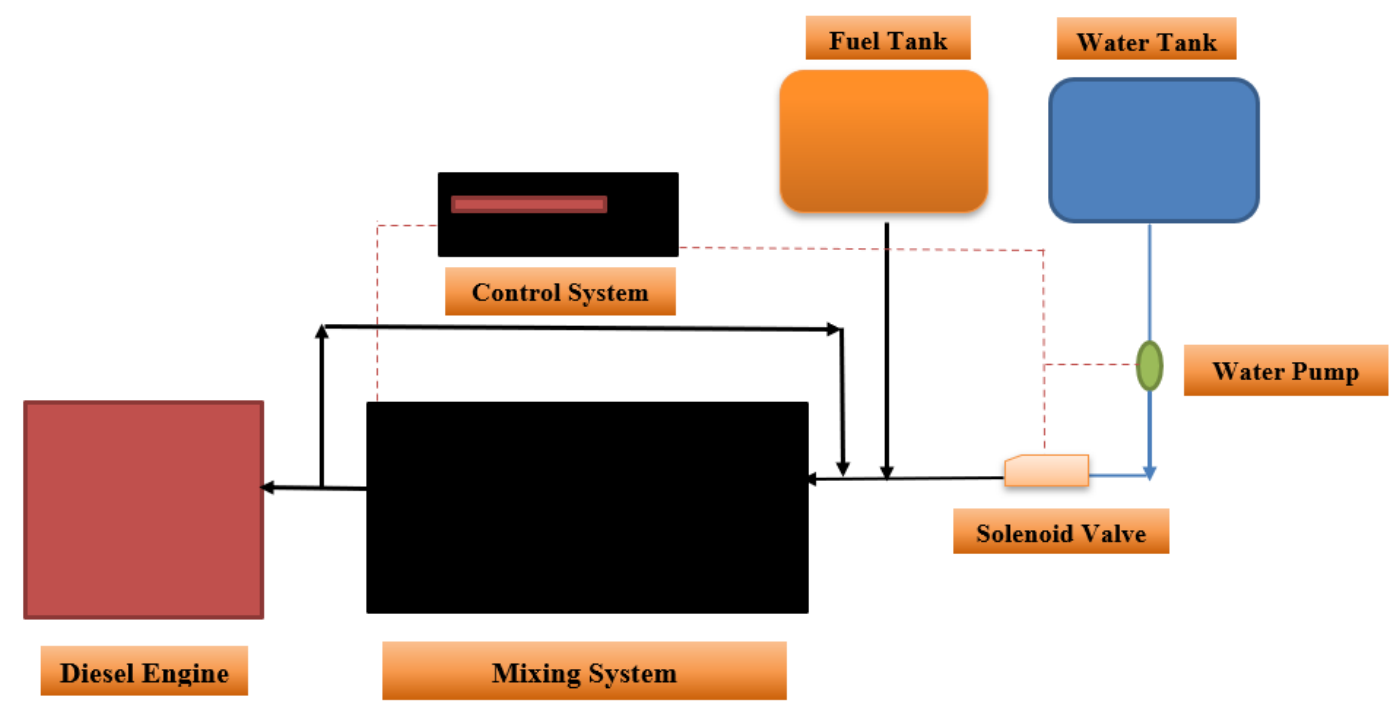

Fig. 1. Configuration of mixing system

\subsection{Engine Testing}

A diesel engine with a 4-stroke, single cylinder, air-cooled direct injection was used. Other basic engine specifications are shown in Table 1. The engine test setup design diagram is shown in Figure 2 This test was carried out with a different load variation from (1-4) kW and constant speed of 3200 $\mathrm{rpm}$. For engine emission measurement, ECOM J2KN Pro was used for acquisition of the emission of $\mathrm{NO}_{x}, \mathrm{CO}$ and $\mathrm{CO}_{2}$. A probe is mounted within the engine's exhaust tail pipe to study the exhaust emission from the engine. The sampling pump will dilute the exhaust gases and go into the sensor for emission for process reading and measurement. The measured data may be passed directly to the program or displayed in the control unit. ECOM J2KN is fitted with ECOM PC Logger software for the recording of test results. For discussion, the measurement is registered within 2 minutes of the engine running duration for every 5 second interval. The average data will then be computed.

Table 1

Engine specifications

\begin{tabular}{ll}
\hline Parameter & Specifications \\
\hline Engine type & 4-Stroke, Single Cylinder, Air-Cooled, Direct Injection Diesel Engine \\
Cooling System & Force air cooling by flywheel \\
Bore x Stroke $(\mathrm{mm})$ & $86 \times 70$ \\
Displacement Volume (Liter) & 0.406 \\
Compression Ratio & 19.3 \\
Maximum Power $(\mathrm{kW})$ & 5 \\
Rated revolution $(\mathrm{rpm})$ & 3200 \\
\hline
\end{tabular}


1. Diesel engine 2. Circulation System 3. Alternator 4. Load

5. Emission analyzer \& Smoke Meter 6. Computer display

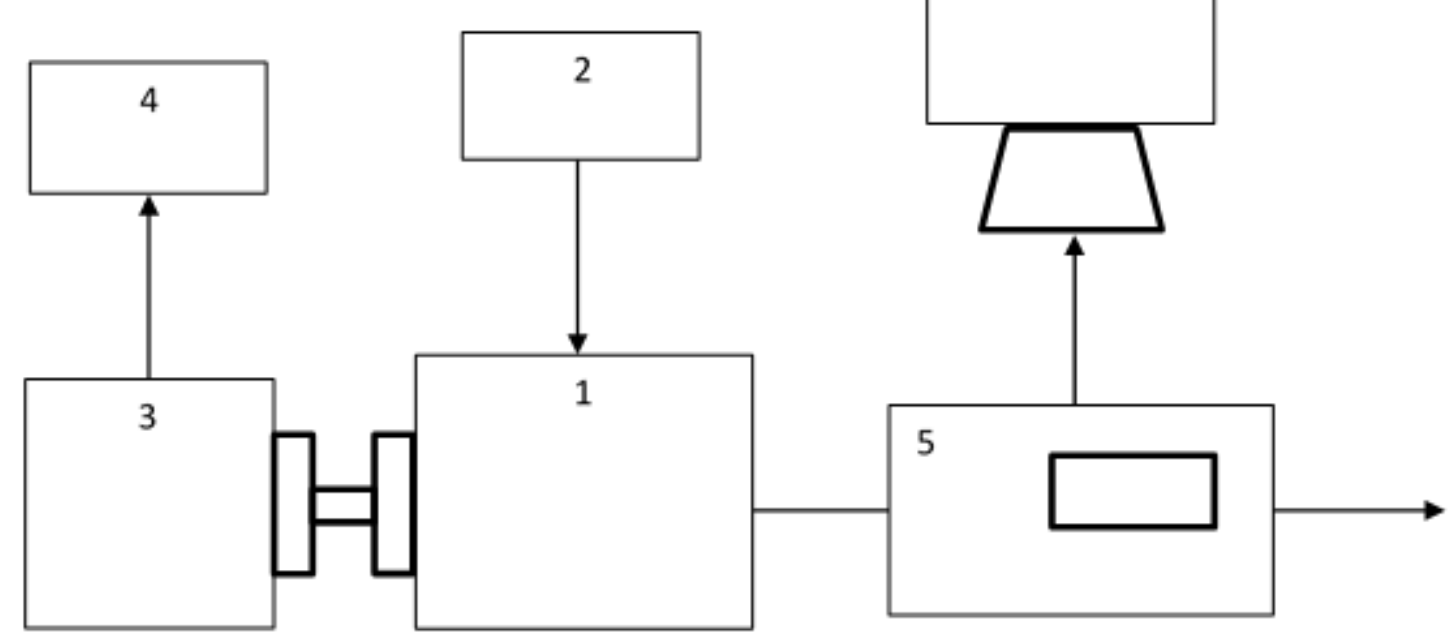

Fig. 2. Engine testing setup

As for the smoke density, the automated smoke meter Horiba M6XA was used. By raising the sample gas volume with a variable sampling method, some of the models are line-upped to conform to low smoke emission level and automatically take sample gas and feed a filter paper to calculate the level of filter blackening. Effective measurement is carried out automatically without personal errors by simply pressing a button to sample exhaust gas, measure reflectance effects and purge air sample lines. The Horiba M6XA model uses a low-drift temperature compensated detector to increase repeatability for less-smoke conditions. The variable sampling method is often used to increase the amount of sample gas and sensitivity in extremely low conditions with smoke. A CAMRY Electronic Kitchen Scale Weighing Scale model EK9620K15- is used to calculate the weight of water consumption. The weighing scale has highly accurate strain gauge sensors that provide accurate measurements from $1 \mathrm{~g}$ to a maximum capacity of $10 \mathrm{~kg}$. For the water weight is taken in this experiment before and after the test. The difference between the two measurements is determining the consumption.

\subsection{Experimental Error}

The experimental error should be considered, as it demonstrates the consistency of the assessments and the obtained data. The complexities have been reduced to some degree for all the calculated parameters by systematically preparing the experiments, regulating the experimental environment and the establishment of a reliable data acquisition and calibration method for measuring devices. 


\section{Results}

\subsection{Fuel Consumption}

Engine fuel consumption powered by D2 and various water percentages (3\%, 6\%, 9\%) NWD with various load parameters at a continuous speed of $3200 \mathrm{rpm}$ is described in Figure 3 . For all calculated fuels, just diesel was recognized for. For this reason, water content was not taken for calculation in the NWD. From the graph it can be observed that with different load conditions fuel consumption almost remains same comparing with D2. However, Once the load is raised, fuel consumption decreases suggesting that engine efficiently consumes fuel at high load on engine. Emulsions increase the delay in ignition compared to pure diesel and enables as much fuel to combust in pre-mixed combustion [21]. The decrease in fuel usage for NWD is ascribed to the occurrence of micro-explosion induced by the disparity of variability between water and diesel. Because of the rapid and strong evaporation of the fuel droplets within larger droplets in diesel, this causes secondary atomization [22]. The $6 \%$ of water in NWD have reduced the highest percentages of fuel consumption by $3 \%$ at 3 $\mathrm{kW}$ load compare to D2. Average reduction of fuel consumption for $3 \%$ and $6 \%$ water are $0.384 \%$ and $1.10 \%$ respectively comparing to D2. However, the average fuel consumption of $9 \%$ of emulsion fuel increased by $1.38 \%$.

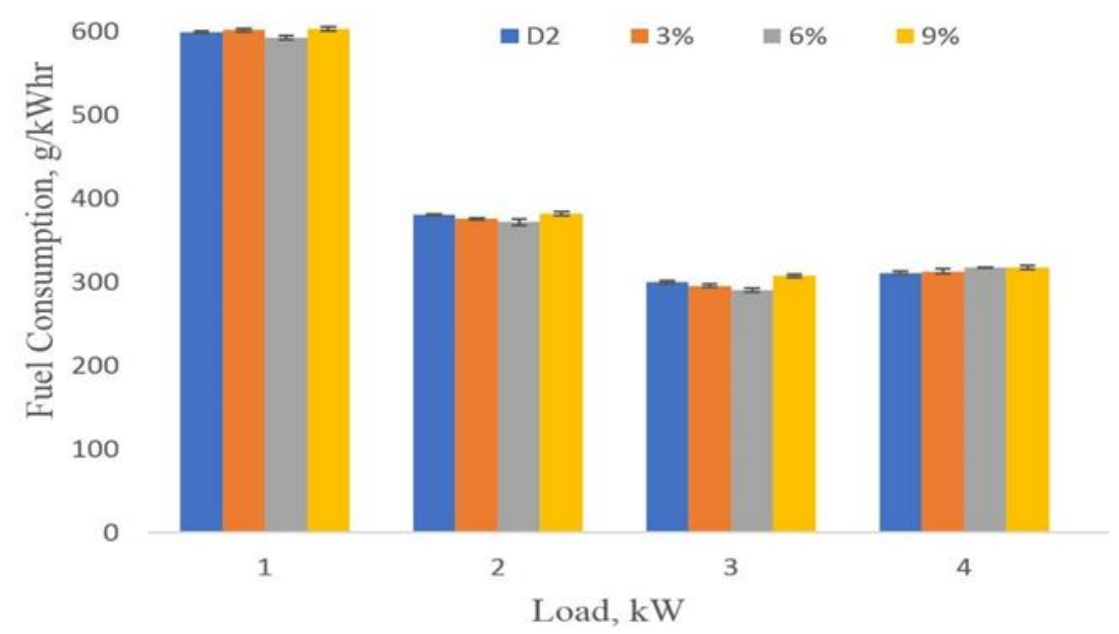

Fig. 3. Fuel consumption under load conditions

\subsection{Exhaust Temperature}

Figure 4 illustrates exhaust temperature of D2, 3\%, $6 \%$ and $9 \%$ of NWD under varying load condition and a constant speed of $3200 \mathrm{rpm}$. This can be deduced as from graph that the engine exhaust temperature also increases as the load increases. The graph shows a trend as the water percentages increases exhaust temperature decreases compare to D2. This can be found that use of NWD minimized the temperature of the exhaust. It's because the water phase absorbed the combustion heat [15]. The water droplets that were scattered absorb heat of the combustion process; therefore, decreasing flame temperature [23]. Overall, when compared to D2, 9\% emulsion fuel Shows the lowest exhaust temperature value, with an average decrease of $7.10 \%$. 


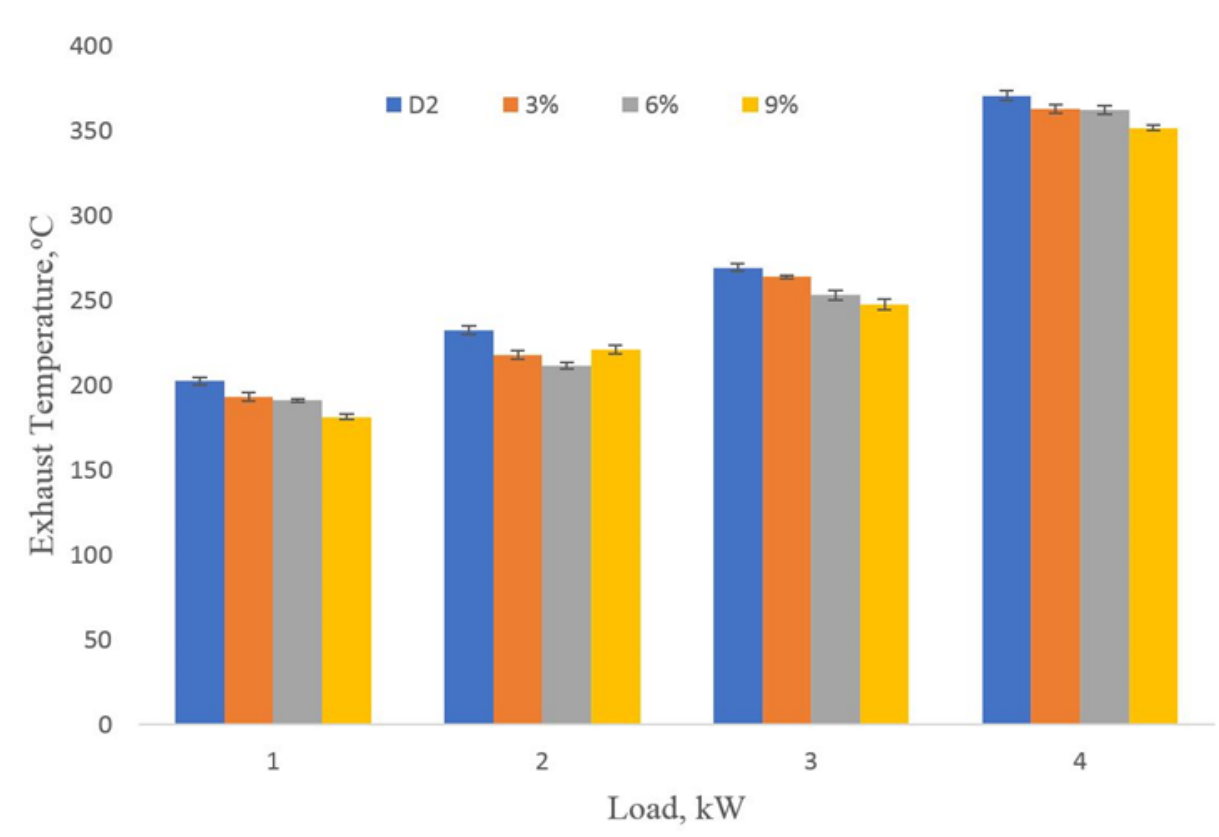

Fig. 4. Exhaust temperature under load conditions

\section{3 $\mathrm{NO}_{\mathrm{x}}$ Emission}

Figure 5 shows that $\mathrm{NO}_{\mathrm{x}}$ emission reduces for all NWD compare to $\mathrm{D} 2$. This happens due to suppressed combustion temperature [24]. At a higher gas temperature, nitrogen $\left(N_{2}\right)$ is oxidized to nitrogen monoxide (NO) and easier to combine with oxygen $\left(\mathrm{O}_{2}\right)$ to produce nitrogen dioxide $\left(\mathrm{NO}_{2}\right)$ [25]. Throughout the process, NWD use has been shown to produce less $\mathrm{NO}_{\mathrm{x}}$ in comparison to D2. Water in NWD decreases the average temperature of the flame due to the substantial permeability of the residual heat of water vaporization throughout the combustion cycle [26]. Higher water percentages resulted in more reduction of $\mathrm{NO}_{\mathrm{x}}$ compare to other NWD. This is caused by the absorption of heat by the content of water in the NWD. The present of water lowered the temperature of the flame which decreased the emission of NO. Moreover, during the production of $\mathrm{OH}$ radicals by water ionization, oxygen atoms were consumed and thus the concentration of NO decreased even further [27]. When all the NWD compared to D2, 9\% of water showed the lowest $\mathrm{NO}_{\mathrm{x}}$ emission than all other emulsion fuel. $9 \%$ of water emitted 6.57 to $14.61 \%$ less $\mathrm{NO}_{\mathrm{x}}$ than $\mathrm{D} 2$, while average reduction for $6 \%$ and $3 \%$ water are $4.68 \%$ and $0.60 \%$ respectively. 


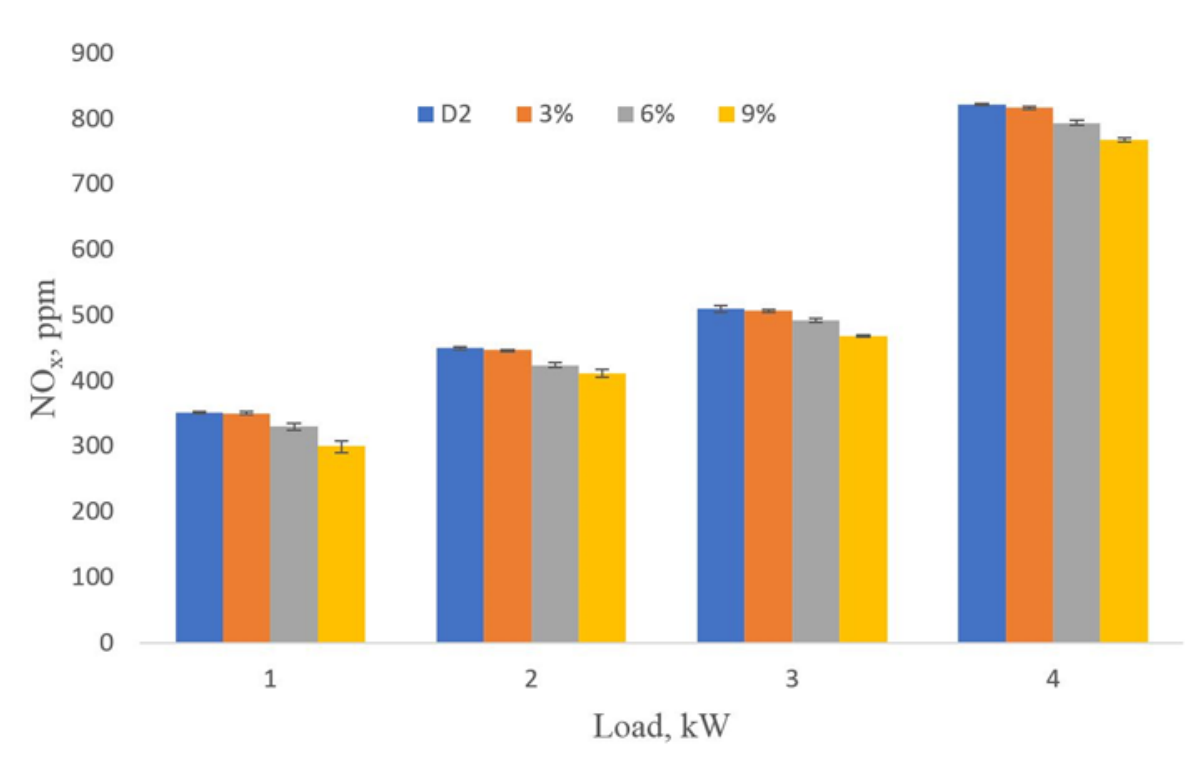

Fig. 5. $\mathrm{NO}_{\mathrm{x}}$ emission under load conditions

\subsection{CO Emission}

Figure 6 shows, CO emissions reduces as the load increases with D2 and NWD. In a diesel engine, $\mathrm{CO}$ deposition triggered by incomplete oxidation of the fuel and slow soot burning during the final combustion process. NWD tends to cause increment in $\mathrm{CO}$ emission. Higher water percentages tend to reduce more exhaust temperature thus resulting in lower temperature in combustion which causes reduction to convert $\mathrm{CO}$ to $\mathrm{CO}_{2}$. The presence of water within the NWD has reduced the temperature of combustion resulting in increased formation of $\mathrm{CO}$. Once the combustion for the temperature goes below $1400 \mathrm{~K}, \mathrm{CO}$ to $\mathrm{CO}_{2}$ oxidation freeze due to temperature insufficiency. Overall, the lower fuel combustion temperature produces higher $\mathrm{CO}$ emissions than diesel fuel. Diesel engine works well with lean mixtures of fuel, CO emissions are normally low in the exhaust [11]. Figure 6 illustrates, overall CO emission using NWD increased when compared to D2. Water of $9 \%$ shows the highest average CO emission compare to D2 which is $40.99 \%$. Meanwhile, the other NWD also showed increased CO emission when compared to D2.

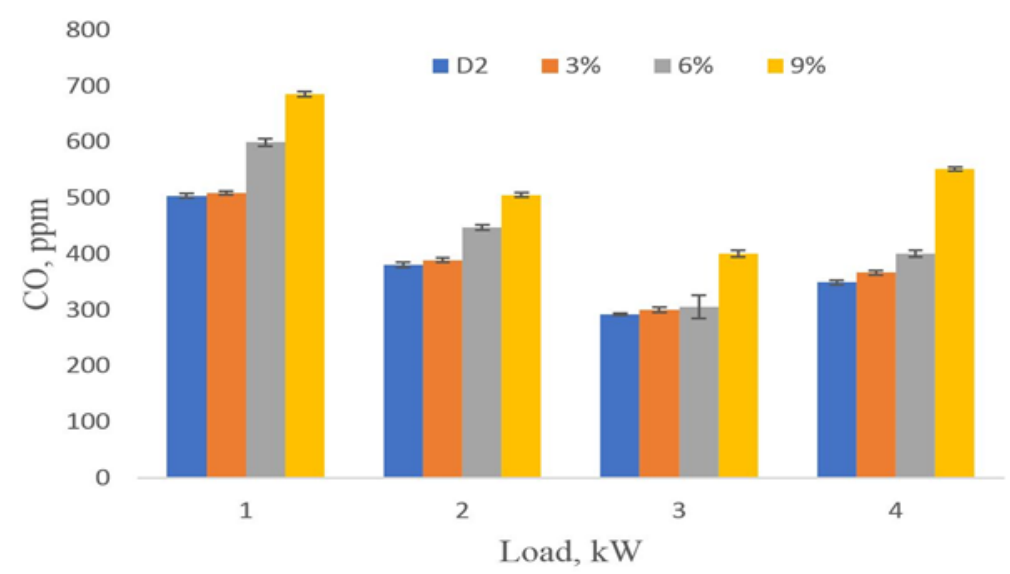

Fig. 6. CO emission under load conditions 


\subsection{Smoke Emission}

Figure 7 describes the smoke number against various load condition (1-4) kW with a continuous speed of $3200 \mathrm{rpm}$ comparing to D2 with different water percentages (3\%, 6\% and 9\%). Smoke production occurs due to inadequate combustion of the fuel and carbon content of the fuel [8]. There are two types of smoke produces while using emulsion fuel, black smoke and white smoke. But white smoke is more dominant while using emulsion. While detecting smoke for emulsion smoke meter sums up black and white smoke for value. However, if use filter to trap particulate matter the result for $\mathrm{pm}$ emission will reduce using emulsion. It is noticeable that $6 \%$ emulsion reduced smoke emission in all load conditions compare to D2. Using $9 \%$ emulsion fuel smoke increases drastically.

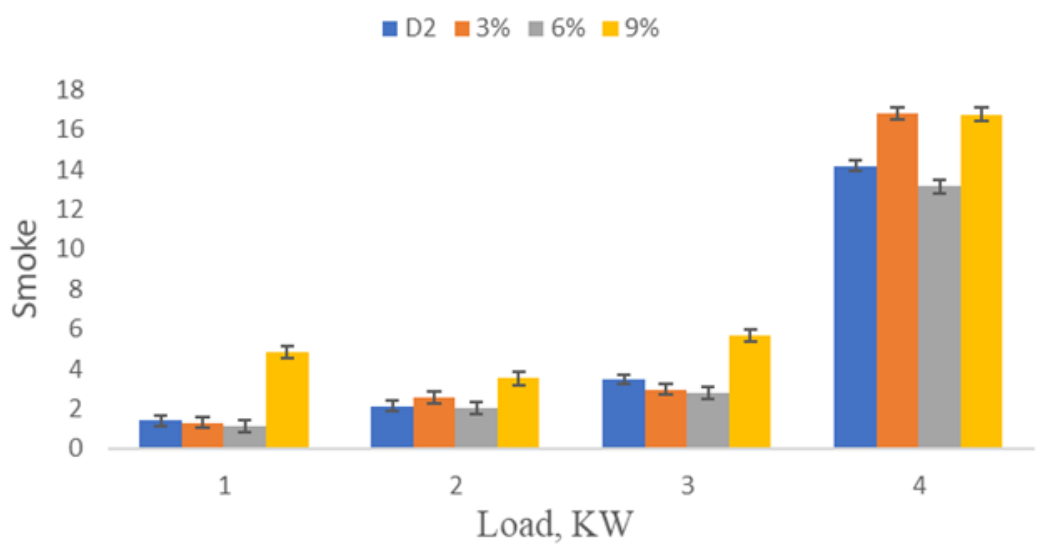

Fig. 7. Smoke emission under load conditions

\section{Conclusions}

The use of NWD is feasible. The $\mathrm{NO}_{\mathrm{x}}$ emissions of diesel can be lowered by introducing into the fuel with water to create an emulsion. The lowered $\mathrm{NO}_{x}$ emission is achieved at the expense of increased CO emissions. The $6 \%$ water content in NWD is consistent lowered fuel consumption and $\mathrm{NO}_{x}$ compare to others. Using 9\% water content in NWD lowered $\mathrm{NO}_{\mathrm{x}}$ and increased $\mathrm{CO}$. With all water content in the NWD, the $\mathrm{CO}_{2}$ emissions were reduced significantly. A new concept to produces NWD by using CS is another method that can be applied

\section{Acknowledgement}

We would like to express gratitude to the Malaysia-Japan International Institute of Technology (MJIIT), Universiti Teknologi Malaysia for providing the facilities and equipment for this research. Highest appreciation goes to the Ministry of Education Malaysia and Universiti Teknologi Malaysia for the financial support through UTM High Impact Research Grant (Q.K130000.2443.08G98)

\section{References}

[1] Zulkurnai, Fatin Farhanah, Norhidayah Mat Taib, Wan Mohd Faizal Wan Mahmood, and Mohd Radzi Abu Mansor. "Combustion Characteristics of Diesel and Ethanol Fuel in Reactivity Controlled Compression Ignition Engine." Journal of Advanced Research in Numerical Heat Transfer 2, no. 1 (2020): 1-13. https://doi.org/10.37934/cfdl.13.2.111

[2] Ramlan, N. A., A. A. Abdullah, and W. J. Yahya. "Combustion Performance and Exhaust Emission Analysis of Diesel Engine using Waste Cooking Oil." Journal of Advanced Research in Fluid Mechanics and Thermal Sciences 12, no. 1 (2015): 11-20. 
[3] Erdiwansyah, Mahidin, Yusop, Ahmad Fitri, Muhammad Zaki, Rizalman Mamat, Ratna Eko Sardjono, Nor Azwadi Che Sidik, and Husni Husin. "Investigation of The Effect Biodiesel-Butanol-Water Fuel Blend Pressure on A SingleCylinder Diesel Engine." Journal of Advanced Research in Fluid Mechanics and Thermal Sciences 79, no. 2 (2021): 39-47. https://doi.org/10.37934/arfmts.79.2.3947

[4] Mahdi, Wan Nur Izzati Wan, Ahmad Muhsin Ithnin, Wira Jazair Yahya, Muhammad Adib Abdul Rashid, Muhamad Aliff Zaharim, Mikhael Mukhlasein Ahmad, Hasannuddin Abd Kadir, and Ili Fatimah Abdul Razak. "Effect of Electrical Load On the Emulsification Methods of Inline Mixing System RTES Produced by The Static Mixer and Ultrasonic on Fuel Consumption and Emission Characteristics." Journal of Advanced Research in Fluid Mechanics and Thermal Sciences 78, no. 1 (2021): 88-99. https://doi.org/10.37934/arfmts.78.1.8899

[5] Ahmad, Mohamad Azrin, Wira Jazair Yahya, Ahmad Muhsin Ithnin, A. K. Hasannuddin, Muhammad Aiman Abu Bakar, Abdul Yasser Abd Fatah, Nor Azwadi Che Sidik, and Hirofumi Noge. "Combustion performance and exhaust emissions fuelled with non-surfactant water-in-diesel emulsion fuel made from different water sources." Environmental Science and Pollution Research 25, no. 24 (2018): 24266-24280. https://doi.org/10.1007/s11356-018-2492-2

[6] Bertola, Andrea, Renxian Li, and Konstantinos Boulouchos. "Influence of water-diesel fuel emulsions and EGR on combustion and exhaust emissions of heavy duty DI-diesel engines equipped with common-rail injection system." SAE transactions (2003): 2244-2260. https://doi.org/10.4271/2003-01-3146

[7] Kadota, T., and H. Yamasaki. "Recent advances in the combustion of water fuel emulsion." Progress in energy and combustion science 28, no. 5 (2002): 385-404. https://doi.org/10.1016/S0360-1285(02)00005-9

[8] Ramlan, Nur Atiqah, Wira Jazair Yahya, Ahmad Muhsin Ithnin, A. K. Hasannuddin, Siti Amiliyana Norazni, Nurul Aiyshah Mazlan, Dhani Avianto Sugeng, Nadia Dayana Bahar, and Tsuyoshi Koga. "Performance and emissions of light-duty diesel vehicle fuelled with non-surfactant low grade diesel emulsion compared with a high grade diesel in Malaysia." Energy Conversion and Management $130 \quad$ (2016): $192-199$. https://doi.org/10.1016/i.enconman.2016.10.057

[9] Maiboom, Alain, and Xavier Tauzia. "NOx and PM emissions reduction on an automotive HSDI Diesel engine with water-in-diesel emulsion and EGR: An experimental study." Fuel 90, no. 11 (2011): 3179-3192. https://doi.org/10.1016/i.fuel.2011.06.014

[10] Hasannuddin, A. K., J. Y. Wira, S. Sarah, M. I. Ahmad, S. A. Aizam, M. A. B. Aiman, S. Watanabe, N. Hirofumi, and M. A. Azrin. "Durability studies of single cylinder diesel engine running on emulsion fuel." Energy 94 (2016): 557-568. https://doi.org/10.1016/i.energy.2015.10.144

[11] Hasannuddin, A. K., J. Y. Wira, R. Srithar, S. Sarah, M. I. Ahmad, S. A. Aizam, M. A. B. Aiman et al. "Effect of emulsion fuel on engine emissions-A review." Clean Technologies and Environmental Policy 18, no. 1 (2016): 17-32. https://doi.org/10.1007/s10098-015-0986-x

[12] Subramanian, K. A. "A comparison of water-diesel emulsion and timed injection of water into the intake manifold of a diesel engine for simultaneous control of NO and smoke emissions." Energy Conversion and Management 52, no. 2 (2011): 849-857. https://doi.org/10.1016/j.enconman.2010.08.010

[13] Wang, Zhaowen, Shuguo Shi, Sheng Huang, Jie Tang, Tao Du, Xiaobei Cheng, Ronghua Huang, and Jyh-Yuan Chen. "Effects of water content on evaporation and combustion characteristics of water emulsified diesel spray." Applied energy 226 (2018): 397-407. https://doi.org/10.1016/j.apenergy.2018.06.023

[14] Bidita, B. S., A. R. Suraya, M. A. Shazed, M. A. Mohd Salleh, and A. Idris. "Influence of fuel additive in the formulation and combustion characteristics of water-in-diesel nanoemulsion fuel." Energy \& fuels 28, no. 6 (2014): 4149-4161. https://doi.org/10.1021/ef5002259

[15] Hasannuddin, A. K., J. Y. Wira, S. Sarah, WMN Wan Syaidatul Aqma, AR Abdul Hadi, N. Hirofumi, S. A. Aizam et al. "Performance, emissions and lubricant oil analysis of diesel engine running on emulsion fuel." Energy conversion and management 117 (2016): 548-557. https://doi.org/10.1016/i.enconman.2016.03.057

[16] Ochoterena, Raúl, Anna Lif, Magnus Nydén, Sven Andersson, and Ingemar Denbratt. "Optical studies of spray development and combustion of water-in-diesel emulsion and microemulsion fuels." Fuel 89, no. 1 (2010): 122132. https://doi.org/10.1016/j.fuel.2009.06.039

[17] Zeng, Yangbing, and F. Lee Chia-fon. "Modeling droplet breakup processes under micro-explosion conditions." Proceedings of the Combustion Institute 31, no. 2 (2007): 2185-2193. https://doi.org/10.1016/j.proci.2006.07.237

[18] Ganesan, S., and A. Ramesh. Investigation on the use of Water-Diesel Emulsion in a LPG-Diesel Dual Fuel Engine. No. 2001-28-0032. SAE Technical Paper, 2001. https://doi.org/10.4271/2001-28-0032

[19] Cui, Xiaoqi, Arjan Helmantel, Valeri Golovichev, and Ingemar Denbratt. Combustion and emissions in a light-duty diesel engine using diesel-water emulsion and diesel-ethanol blends. No. 2009-01-2695. SAE Technical Paper, 2009. https://doi.org/10.4271/2009-01-2695 
[20] Abu-Zaid, M. "Performance of single cylinder, direct injection diesel engine using water fuel emulsions." Energy conversion and Management 45, no. 5 (2004): 697-705. https://doi.org/10.1016/S0196-8904(03)00179-1

[21] Ithnin, Ahmad Muhsin, Mohamad Azrin Ahmad, Muhammad Aiman Abu Bakar, Srithar Rajoo, and Wira Jazair Yahya. "Combustion performance and emission analysis of diesel engine fuelled with water-in-diesel emulsion fuel made from low-grade diesel fuel." Energy Conversion and Management 90 (2015): $375-382$. https://doi.org/10.1016/i.enconman.2014.11.025

[22] Lif, Anna, and Krister Holmberg. "Water-in-diesel emulsions and related systems." Advances in colloid and interface science 123 (2006): 231-239. https://doi.org/10.1016/i.cis.2006.05.004

[23] Watanabe, Hirotatsu, Yohsuke Matsushita, Hideyuki Aoki, and Takatoshi Miura. "Numerical simulation of emulsified fuel spray combustion with puffing and micro-explosion." Combustion and flame 157, no. 5 (2010): 839852. https://doi.org/10.1016/i.combustflame.2010.01.013

[24] Hsu, Bertrand D. "Combustion of water-in-diesel emulsion in an experimental medium speed diesel engine." SAE transactions (1986): 285-296. https://doi.org/10.4271/860300

[25] Heywood, John B. "Combustion engine fundamentals. 1a Edição." Estados Unidos (1988).

[26] Maiboom, Alain, and Xavier Tauzia. "NOx and PM emissions reduction on an automotive HSDI Diesel engine with water-in-diesel emulsion and EGR: An experimental study." Fuel 90, no. 11 (2011): 3179-3192. https://doi.org/10.1016/i.fuel.2011.06.014

[27] Samec, Niko, Robert W. Dibble, Jyh Y. Chen, and Andrej Pagon. Reduction of NOx and soot emission by water injection during combustion in a diesel engine. No. 2000-05-0079. SAE Technical Paper, 2000. 